Téoros

Revue de recherche en tourisme

\title{
Le Saint-Laurent, patrimoine du Québec
}

\section{Alain Duhamel}

Volume 6, numéro 2, juillet 1987

Le Saint-Laurent magnétique

URI : https://id.erudit.org/iderudit/1080501ar

DOI : https://doi.org/10.7202/1080501ar

Aller au sommaire du numéro

Éditeur(s)

Université du Québec à Montréal

ISSN

0712-8657 (imprimé)

1923-2705 (numérique)

Découvrir la revue

Citer cet article

Duhamel, A. (1987). Le Saint-Laurent, patrimoine du Québec. Téoros, 6(2), 4-5. https://doi.org/10.7202/1080501ar d'utilisation que vous pouvez consulter en ligne.

https://apropos.erudit.org/fr/usagers/politique-dutilisation/ 


\title{
Le Saint-Laurent, patrimoine du Québec
}

\author{
par Alain Duhamel*
}

Fascinant. D'où qu'il se montre aux promeneurs de ses rives, le Saint-Laurent les fascine tous; impossible de $s^{\text {'en distraire }}$ dès lors qu'il capte le regard!

Un fleuve? Si grand que son nom même se confond en anses, en baies, en lacs, en fleuve, en estuaire, en golfe; en eau douce, puis en eau salée; en cours calme, puis en cours impétueux.

Pierre Boucher, dans son Histoire véritable et naturelle, le décrit ainsi à l'intendant Colbert, conseiller du Roy:

La Nouvelle-France est un très grand pays qui est coupé en deux par un grand fleuve nommé fleuve Saint-Laurent. Son embouchure commence a Gaspé et a cinquante lieues de large. Pour sa longueur, nows $n$ 'en savons autre chose sinon qu'il prend son origine du lac des Hurons, autrement appele Mer-douce, que l'on tient awoir environ trois cents lieues de contour; de sorte qu'il se trouve que, depuis Gaspe jusqu "audit lac, il y a près de cinq cents lieues par le circuit qu'elle fait. ${ }^{\text {(1) }}$

Un fleuve au centre et au coeur du pays. La, dans ses îles et sur ses rives, commence une histoire. Il en subsiste des témoins tout au long de son parcours.

Le Saint-Laurent exerce toute sa fascination par les lieux où est possible d'entrer en intimité avec lui; des lieux, trop rares de nos jours, où les rêves s'enfuient dans le paysage fluvial à en perdre jusqu'à la notion du temps présent. Il n'est de meilleur endroit que dans les îles.

Tout près de Montréal, sur l'île Perrot, à la Pointe-du-Moulin, se trouve un point d'observation au ras de l'eau. Le moulin à vent, construit au début du XVIII ${ }^{e}$ sic̀cle, avait, tous les printemps, avant que le fleuve ne prenne son lit d'été, les pieds dans l'eau. Depuis sa restauration en un pare provincial, il parvient habituellement à se tenir au sec. De la pointe basse qui tranche dans l'eau, le regard du promeneur,

"Alain Duhamel fut journaliste as Devoir où if fitait res-
ponable, entre autres, de la chronique sur le ponsable, porté par un fleuve plat, embrasse un panorama montréalais unique: 1'horizon se découpe entre le clocher de la vieille église de Pointe-Claire, le dôme de l'oratoire Saint-Joseph, l'université, le mont Royal et les gratte-ciel du centre-ville.

De ce point de vue, rien ne laisse soupçonner les rapides de Lachine. Pour les observer, il faut parcourir la rive de la ville de LaSalle. Pour ceux qui ont le coeur bien accroché, il est possible de descendre les rapides en été à partir d'excursions au port de Montréal.

Aux îles Saint-Hélène et Notre-Dame, les vestiges de Terre des Hommes distraient. Le fleuve est ici port et voie maritime.

Nous n'avons pas le sentiment de retrouver le même fleuve depuis l'île SainteThérèse ou depuis les illes de Boucherville. L'activité maritime et la proximité urbaine seraient-elles dérangeantes à ce point? Le fleuve y est habituellement gris, même par beau temps.

Il faut aller plus loin, vers le lac SaintPierre, pour retrouver le fleuve dans toute sa richesse naturelle. Au sud, dans les illes de Sorel, au chenal du moine, se tiennent encore debout sur leurs pilotis, les habitations des Beauchemin, des Salvail et du Survenant de Madame Guèvremont. L'été, les chenaux deviennent les boulevards du hors-bord... De l'autre cóté, des milliers d'oies et de canards font au printemps des champs de neige volante dans les marais de la plaine d'inondation.

Plus loin encore, au-delà du Saint-Maurice, le fleuve se rétrécit pour se faufiler entre Lotbinière et Portneuf. A Deschambault, sur une pointe élevée, derrière l'église, se présente un paysage fluvial aussi loin que le regard puisse porter. Jusqu'à Québec, le Saint-Laurent a des allures de fleuve, comme si les oceaniques devaient prendre garde de s'6corcher sur les rives toutes proches.

Passée la pince de Québec et Lévis, l'ũle d'Orléans parait offrir deux fleuves, l'un sur la cóte de Beaupré, l'autre sur la cóte de Bellechasse, avant de se méler en estuaire. De la pointe nord de l'île, près de Saint-François, une large vue donne sur tout le fleuve. II s'agit de I"un des derniers endroits où il soit encore possible de lire le fleuve d'une rive à l'autre. Après, il s'elargit tant qu'il faut compter sur un jour sans brouillard ni nuage pour distinguer au nord et au sud le clocher d'un village.

Le cap Tourmente s"élève comme un rempart dans les basses terres. A son pied se trouve l'un des plus importants sanctuaires d'oies sauvages. Un centre d'interprétation permet de s'instruire de la vie de ses grandes routières du fleuve.

Jusqu'au fjord du Saguenay, point de rassemblement des belugas et autres grands mammiferes marins, la côte de Charlevoix offre de nombreux points de vue dominants d'où l'on aperçoit des îles. Me aux Coudres, ile aux Grues, île aux Oies, beaucoup plus iles de mer que fluviales, elles ont conservé longtemps le paysage du pays au siècle dernier, avant que l'automobile ne le redessine complètement.

La côte caillouteuse du Sud donne accès au fleuve par les quais, la plupart abandonnés aujourd'hui. Des villages marins: CapSaint-Ignace, L'Islet-sur-Mer, Saint-JeanPort-Joli, Saint-Roch-des-Aulnaies, La Pocatière et jusqu'à la côte gaspésienne, haute comme une forteresse, comme si elle devait résister à cet océan qui l'échancre et la perce. En face, le Saint-Laurent fait oeuvre d'art dans les îles de Mingan, laissant sculptures et reliefs.

Nulle part, sur tout son trajet, on ne trouve un endroit où des moyens aussi simples que des tables de lecture du paysage, qui permettraient aux promeneurs de faire plus ample connaissance avec le patrimoine naturel du fleuve. Ainsi, les routes anciennes (la 132 et la 138) offrent des points de vue qu'il faut découvrir soi-méme, au fil des voyages entrepris sans se presser. En même temps, elles conduisent vers le patrimoine culturel du Saint-Laurent, étalé de villages et de villes en un long corridor de part et d'autre. 
Un seul endroit ouvre le fleuve sur sa préhistoire. A la Pointe-du-Buisson, près de Melocheville, se trouvait une station de pêche iroquoienne. Les fouilles archéologiques entreprises depuis le milieu des années 1960 ont mis à jour un témoignage particulièrement riche de la vie des pêcheurs amérindiens, témoignage recons. titué dans un centre d'interprétation ouver au public depuis 1986. Ailleurs, les fouilles archéologiques ont, certes, retracé d'autres établissements amérindiens, mais aucun chantier n'a abouti à un lieu d'éducation et d'interprétation aussi élaboré

Le Saint-Laurent a mille et une histoires qui se racontent encore...
Celle du commerce de la fournure à Lachine, ou celle d'un canal fortifié, a la Pointe-du-Lac. Celle d'un phare à la pointe des Monts ou celle des goélettes charlevoisiennes à l'ile aux Coudres.

Des villes ont pris du caractère en fréquentant le fleuve: Quebec, montée sur son cap. le tient en joue depuis sa citadelle; Montréal, qui n'a pas voulu conserver ses murs, en a fait un port de mer en eau douce où, entre autres, hibernent les barges des Grands lacs.

Il y a encore des histoires à raconter comme celle de la navigation à vapeur qui se prépare au musée David-Stewart, à mesure que

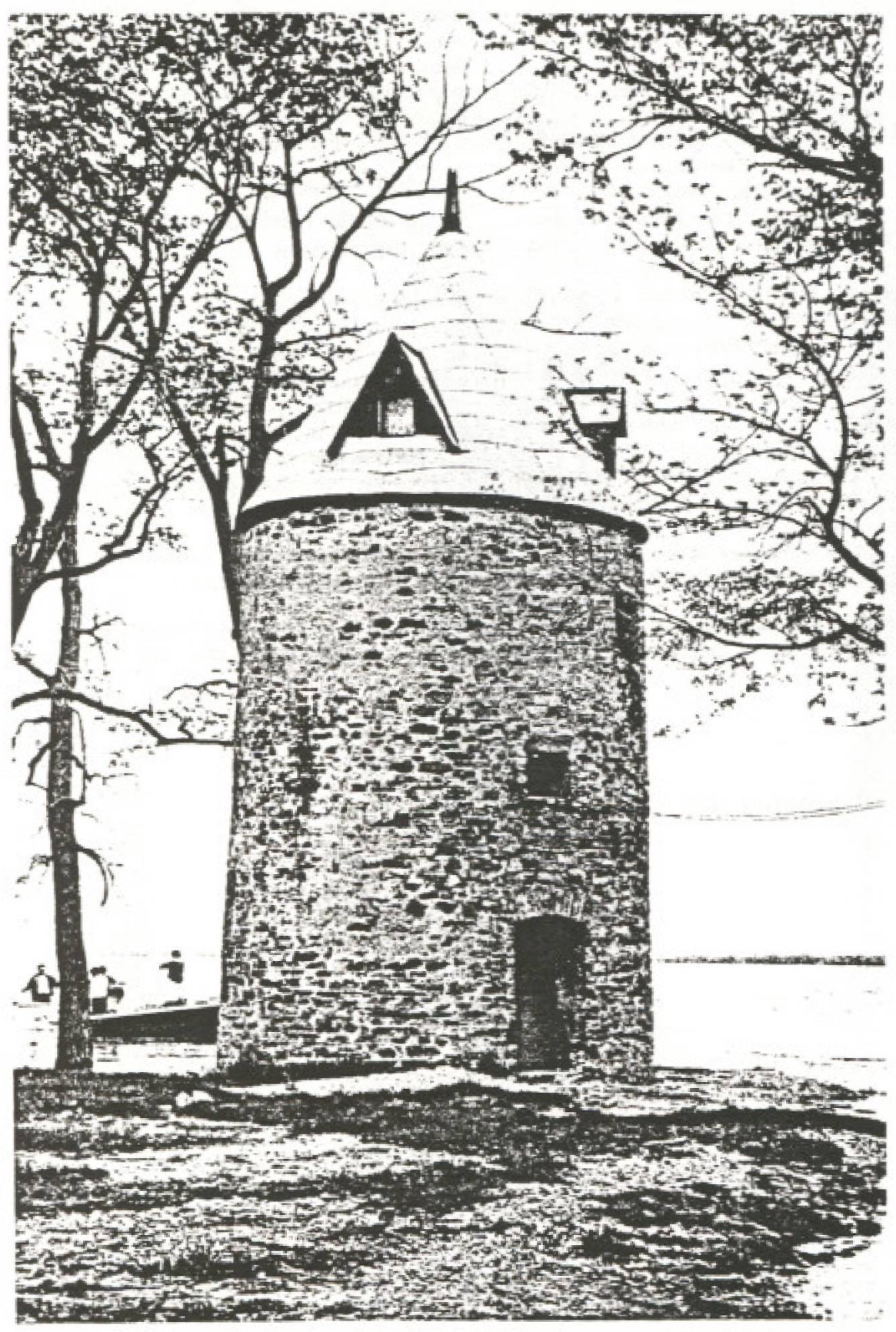

Le moulin de I'lle Perrot les plongées révèlent chaque été un peu plus de renseignements sur les premiers vapeurs de la famille Molson.

Le chapitre de 1'histoire maritime le plus élaboré se trouve à l'Islet-sur-Mer où le musée maritime Joseph-E.-Bernier a réuni une collection importante de documents, d'objets et de navires du pays. On y reprend contact avec cet aventurier des mers polaires, le capitaine Bernier de l'Islet; et avec la tragédie de 1'Empress of Ireland au phare-musée de Pointe-au-Père près de Rimouski.

Mais toutes ces histoires ne font pas une tradition. Serait-ce, comme l'affirme JeanClaude Lasserre, que le Saint-Laurent tombe dans la plus parfaite banalité?

Diaxe fondamental de l'organisation-de l'espace et de la société, et mise à part la pèche, elle-mème en grandes difficultés, le Saint-Laurent est devenu pour beaucoup de populations des bords de l'eau un simple élément du paysage. (2)

Ce qui s'impose, pense le Secrétariar du projer Saint-Laurent, qui le proclame ressource nationale prioritaire, c'est sans doute de nouer des liens entre le SaintLaurent, ressource naturelle et commerciale, et le Saint-Laurent, foyer d'histoire et de culture. ${ }^{(3)}$

Car il y a coupure entre le fleuve et son pays.

Les efforts, nombreux mais dispersés, pour mettre en valeur la tradition maritime du Saint-Laurent ne sont pas parvenus encore à le réhabiliter dans les coeurs et dans les esprits. Comment pourrait-il en être autrement à l'égard d'un fleuve égout dans lequel personne n'ose se baigner? A l'égard d'un fleuve dont les rives deviennent artificielles un peu plus chaque année à force de remblayages et de remplissages?

Le fleuve et ses habitants renoueront lorsqu'ils pourront à nouveau vivre ensemble. Alors, ils reinventeront une tradition. Le Saint-Laurent sera non seulement fascinant, il sera aussi merveilleux $f$

\section{Refterences}

(1) Pierre Boucher, Histoire veritable et naturelle des mosurs at productions du pays de la NouvelleFrance, vulgairament dite la Canada, 1664.

(2) Jean-Claude Lasserre, Le Saint-Laurent, une grande porte de l'Amerique, Cahiers du Qubbec, Hurtubise HMH, 1980.

(3) Ouébec, Conseil exécutif, Le Saint-Laurent, ressource nationale prioritaire: rapport du projet Saint-Laurent, Quebec: Ministere des Communications, 1965. 